Ocula ${ }^{15}$

Commemorating Charles S. Peirce (1839-1914):

interpretive semiotics and mass media

A cura di Giampaolo Proni e Salvatore Zingale

Novembre 2014 I www.ocula.it - DOI: 10.12977/ocula37

\title{
Inference in Media Space \\ The Case of IBM Software Executive Briefing Center - Rome
}

\author{
Toni Marino \\ Università per Stranieri di Perugia \\ tonimarino@hotmail.com; toni.marino@unistrapg.it
}

\begin{abstract}
In our paper we apply Peirce's model of Arguments (Statistical Deduction, Probabilistic Deduction, Induction and Abduction) to a communication process where negotiating sense and meanings is emphasized. We selected a communication space where everything is planned as a medium of sense (video terminals, screens, lights, etc.) namely the IBM Software Executive Briefing Center in Italy, a workplace used to exchange views, negotiate or transact. It is based in Rome in the same building as the International Development Laboratory of the IBM Software Group. The Software Center is the place where IBM welcomes its potential customers and has the opportunity to show them its technology and offer solutions.

This paper focuses on "media space" in the Center which is structured by the seller according to his/her idea of the buyer's interpretive process. This paper analyzes the roles of visual codes in the allocation of functions. It also looks into the relation between the symbolism of the company with its marketing, past history and media space in order to define the buyer's typology of inference (deduction, induction or abduction) in relation to the communication strategy of the media space design. The research is conducted directly in the field by interviewing the Manager of the IBM Center as well as asking people who use it to fill in an anonymous questionnaire, which analyses both the media space and the plan of the building.
\end{abstract}

\section{Keywords}

Inference, Media Space, Abduction, IBM, Video terminals

\section{Contents}

1. Introduction

2. Theoretical frame

3. State of the art

4. Methodology

5. Case study: The IBM Briefing Center - Rome 5.1 Media space in IBM Briefing Center 5.2 The point of view of IBM

6. Relevant semiotic processes in media space 6.1 The path of deduction

6.2 The path of induction 6.3 The path of abduction

7. Results of questionnaires

8. Conclusions

References 


\section{Ocula $a^{15}$}

Commemorating Charles S. Peirce (1839-1914): interpretive semiotics and mass media

Toni Marino, Inference in Media Space

\section{Introduction and aims}

Inference is the cognitive process that makes possible an increase in knowledge gained from a database derived from experience. It is a logical process that applies the results of previous observations to new phenomena. Every event in reality is interpreted according to the logic derived from experience. At an advanced level of knowledge, inference is a fairly intricate system where we establish complex relationships between different elements such as general rules, proven knowledge, assumptions of knowledge, symbols of knowledge and semantic chains. At any time during experience our frames of the world - kinds of general patterns of knowledge - undergo a change in quantity and quality.

One of the features of inference is the competition between different scenarios of knowledge starting from a set of inputs and, consequently, the existence of rhetorical devices that support one scenario against another. Prior to this, a "content nebula" (Eco 1976) is validated at the expressive level and undergoes a process of interpretation. What kind of knowledge is it? What is its expressive plan? In this process one should be looking for general rules, either new or already known, which may explain the existence of events in reality or their meaning in a particular cultural community. This is the same process highlighted by the Russian school of semiotics, or by René Thom (1975) in his morphological model, where he speaks of the "path of probability" from pregnancy to salience.

The case of information technology (IT) is particularly interesting because, first of all, it puts a strain on the difference between knowledge as measurement and knowledge as discovery. Generally, IT is a measure of reality: the application of a technological point of view to a process of life (e.g. recruitment of bank staff). But only a small group of people (the bank, project team) knows the general rule to be applied to the situation (algorithm for the evaluation of skills). For other people this type of knowledge is a discovery (e. g. sociologists of work).

IT is interesting because it appears to many people as a discovery, but it does not increase our knowledge of reality. Moreover, we come in contact only with technological devices (video, touch screen, media space, etc.) and in many cases we never learn the technique which produces the technology. The success of an IT product, especially in the case of commodities, is based on its aesthetic appearance.

For some researchers this process is a reversal of anthropological evolution - the function of an organ precedes its creation - which has consequences for the cognitive process of interpreting reality. Simone (2012), for example, uses a biological term - exaptation - to describe this phenomenon, and Ipsen (2003: 192) defines this situation as a "crisis of cognition", related to the impossibility of using collateral information to interpret new media messages.

This paper investigates a particular case of technology as a rhetorical apparatus. We selected a communication space where everything is planned as a medium of sense (video terminals, screens, lights, etc.) namely the IBM Software Executive Briefing Center in Italy, a workplace used to exchange 


\section{Ocula $a^{15}$}

Commemorating Charles S. Peirce (1839-1914): interpretive semiotics and mass media

Toni Marino, Inference in Media Space

views, negotiate or transact. It is based in Rome in the same building as the International Development Laboratory of the IBM Software Group. The Software Center is the place where IBM welcomes its potential customers and has the opportunity to show them its technology and offer solutions. In 2011 the Center was expanded and renovated by the Iosa Ghini Associati Architecture Studio, which reworked the interior design inspired by the graphic theme of the famous "stripes" of the IBM logo. This paper focuses on "media space" in the Center. In particular, it investigates two perspectives used for negotiation: (i) the internal point of view of IBM; (ii) the external point of view of the visitor-client. These points of view correspond to the functions related to the roles of sellers and buyers. The media space is structured by the seller according to his/her idea of the buyer's interpretive process: what does he/she deduce from the position of the videos? How does his/her mind process information about the company? What kind of interpretation does his/her mind elaborate about IBM's IT solutions? Generally, this idea is deduced starting from statistical analysis of the brand-image, the perception of brand know-how and finally the analysis of the target related to a specific topic (in this case Information Technology and media space), which makes it possible to discover customer preferences, consumer habits, favourite colors or the vocabulary used.

\section{Theoretical frame}

The statistical calculation assumes semiotic relevance when based on Peirce's definition of interpretation and his description of the logical processes that make the activation of interpretation possible. Peirce, in distinguishing classes of signs, connects the characteristics of these signs in a logical triangle that links sign, object (in the sense of external referent) and Interpretant. The purpose of the sign is to mean something to someone. Proceeding in his taxonomy, Peirce revives the logical trichotomy of categories which he called Firstness, Secondness and Thirdness. In explaining the third category, Peirce introduces the classification of signs in terms of rheme, decisign (or dicent sign) and argument (or reasoning) (Peirce, $\mathrm{CP}$ 2.250), and about the latter he says:

Tenth: An Argument is a sign whose interpretant represents its object as being an ulterior sign through a law, namely, the law that the passage from all such premisses to such conclusions tends to the truth. [...]

An Argument is always understood by its Interpretant to belong to a general class of analogous arguments, which class, as a whole, tends toward the truth. This may happen in three ways, givin rise to a trichotomy of all simple arguments into Deductions, Inductions, and Abductions. (Peirce, CP, 2.263; 2.266)

Peirce introduces a relationship between what is stated in a single expression and the background of the possible logical statements, equating them in terms of the "tendency to the truth". In explaining the arguments as a relationship between signs and interpretants, he distinguishes the three logical processes of deduction, induction and abduction, thus giving semiotic relevance to the statistical computability. As regards this he states: 


\section{Ocula $a^{15}$}

Commemorating Charles S. Peirce (1839-1914): interpretive semiotics and mass media

Toni Marino, Inference in Media Space

A Deduction is an argument whose Interpretant represents that it belongs to a general class of possible arguments precisely analogous which are such that in the long run of experience the greater part of those whose premisses are true will have true conclusions. Deductions are either Necessary or Probable. [...]

Probable Deductions, or more accurately, Deductions of Probability, are Deductions whose Interpretants represent them to be concerned with ratios of frequency. They are either Statistical Deductions or Probable Deductions Proper. A Statistical Deduction is a Deduction whose Interpretant represents it to reason concerning ratios of frequency, but to reason concerning them with absolute certainty. A Probable Deduction proper is a Deduction whose Interpretant does not represent that its conclusion is certain, but that precisely analogous reasonings would from true premisses produce true conclusions in the majority of cases, in the long run of experience. (Peirce, CP, 2.267; 2.268)

In semiosis it is possible to bring about a statistical relationship between sign and interpretant, that is, a relation between a specific manifestation of a sign and the way it is understood. Furthermore, Peirce speaks about the process of abduction as a mechanism of predetermination stating that:

An Argument from a random Sample, is a method of ascertaining what proportion of the members of a finite class possess a predesignate, or virtually predesignate, quality, by selecting instances from that class according to a method which will, in the long run, present any instance as often as any other, and concluding that the ratio found for such a sample will hold in the long run. Its justification is evident.

An Abduction is a method of forming a general prediction without any positive assurance that it will succeed either in the special case or usually, its justification being that it is the only possible hope of regulating our future conduct rationally, and that Induction from past experience gives us strong encouragement to hope that it will be successful in the future. (Peirce, CP 2.269; 2.270)

The association between arguments and statistics is present in Peirce's reflections from the year 1878 when Deduction, Induction, and Hypothesis was published in Popular Science Monthly. Peirce's theoretical frame offers the possibility to investigate the statistical tendency to truth as an object of analysis. In this paper we do not use statistical resources as instruments of analysis, but we study them as a cognitive process. Inferences in media space are a particular occurrence of this cognitive process and are relevant because, on the one hand, the choice of an argument (Deduction, Induction or Abduction) is stimulated in customers by media space and, on the other, it is prompted by external semantic chains related to the content system (movies, books, advertising, newspaper, etc.).

\section{State of the art}

Certainly it is not possible to use the term "state of the art" in humanistic fields, for two reasons: the absence of a systematic sorting of humanistic research and the absence of measurements of results in many humanistic subjects such as Media Studies and Theory of Communication. Nevertheless it is 


\section{Ocula $a^{15}$}

Commemorating Charles S. Peirce (1839-1914): interpretive semiotics and mass media

Toni Marino, Inference in Media Space

possible to describe the main orientation in the study of logical inferences and the relation between inference and media space.

Inference is a logical process but also a cognitive mechanism of the mind that concerns our capacity to classify our experiences of the world. However, strictly speaking, it could be argued that it is not a logical process since everyone is free to apply illogical or non-logical rules: when we live in a fictional world, for example, we apply the mechanism of inference but from a starting point of the suspension of disbelief (Brandt 2008). An interesting model regarding this topic was elaborated by Mark Turner and Gilles Fouconnier (2003). They speak about conceptual blending of knowledge. According to their network model our mind produces an increment of knowledge starting from two input spaces; following this, the inputs are reworked into a cross-space mapping, a generic mental space and a blended space; this working produces an emergent structure with new information about reality. This model is highly interesting because the "blending" produces a growth of information, either cognitive or emotional. "Interpretive semiotics" unlike the generative model or the semiotics of cultures, is the orientation that best allows researchers to apply a semiotic model linked to recent cognitive results (Petrilli, Ponzio 2005).

In the second case, there are many examples of research projects or single papers on this topic all associated with non-homogeneous areas of study. The study of space and media as narrative elements is closely related to the topics of this paper. It is the classic approach found in Literature, Semiotics or Linguistics which makes in-depth studies of space in narrative processes. If it is true that narrative is an experiential model, the logical process that applies this model to a real object, even in fiction, belongs to another level of study. The logical mechanism of knowledge obeys formal and structured rules rather than cultural trends. That is to say that the logic of thought is stronger than cultural symbolism. This is extremely important in relation to IT and media space, especially when one considers the hypothesis that media has resulted in a caesura in cognitive processes. (Gaines 2014: 106-107; Davies 2008). The problem also concerns the absence of a descriptive semiotic vocabulary for media, which would be useful in addressing the need for critical thinking and media literacy (Gaines 2008). The current research projects that we believe will produce valuable results are those which study the use of media in the dissemination of information. These are very helpful socially and include the Visual Persuasion Project, that aims to promote a better understanding of the practice, theory, and teaching of law in the current screen-dominated, pervasively visual, digital era. The Project was set up in 2005 to study and advance the cultivation of critical visual intelligence, to inspire creative visualizations of evidence, case narratives, policy analysis and legal argumentation as well as to help lawyers, judges, law students and the lay public integrate new visual tools into more traditional (textual and verbal) approaches to legal analysis.

\section{Methodology}

To analyze the inferential processes that characterize the media space we adopted a dual approach: 


\section{Ocula $a^{15}$}

Commemorating Charles S. Peirce (1839-1914): interpretive semiotics and mass media

Toni Marino, Inference in Media Space

1. for inferential processes that the visitor performed in media space, we considered this media space as a text of communication, and used Peirce's categories to interpret it;

2. for inferential processes understood as the cognitive processes that take place in the mind of the visitor, we submitted a questionnaire to those who visit the center.

The double methodology is useful for comparing the interpretive hypothesis - obtained by means of textual analysis - with the results of questioning people directly. In fact, the interpretive analysis correlates visitor's encyclopedia of knowledge with signs in media space but does not take into account the figures actually involved in the communication. The interpretive model analyzes the communication process regardless of the intention of those who communicate. The methodology of the questionnaire helps to have a broader picture of the communication by investigating the direct opinion of people involved in this process.

In order to analyze the media elements and inferential processes related to them, we started from an empirical evaluation of the brand. IBM is a leader in IT and the Briefing Center is a place where relationships between the high value attributed to the IBM corporate image (visitors are very familiar with the IBM brand) and the products are contracted. The Briefing Center receives only a small part of IBM clients, generally those who are undecided or are respected customers. On the basis of this evaluation, we suggested three types of visitors: loyal visitors, curious visitors and skeptical visitors. Each type of visitor puts in place a different inferential process. For each of these processes media space offers an answer aimed at the successful outcome of the negotiation and confirmation of the high value of the brand.

Even for the direct analysis of the visitors, we departed from empirical evaluations. The Center provides media support and the setting for IBM members to showcase the products they have been involved in creating. So it was possible to study both the points of view on media space: those of the members of IBM and the visitors-customers as well as analysing the inferential processes that they put in place. For this reason, we prepared two multiple choice questionnaires, which were distributed to the two types of visitors (see Exhibits 1-2). This was done for two weeks in February 2014 and no assistance was provided in their compilation. The questionnaire, developed by us, was presented as an independent research project and not as one conducted by the IBM group. However, as it was handed out during negotiations, the management of the distribution was carried out by IBM employees who work in the Center.

IBM members were asked questions aimed at gathering information about the empirical communication process such as the utility of the Briefing Center, level of customer knowledge of the IBM brand and relevant elements of the IBM corporate image. In addition, there was a question which was calculated to discover the the visitors' typology of inference, according to IBM members. Specifically, we asked: 


\section{Pcula ${ }^{15}$}

Commemorating Charles S. Peirce (1839-1914): interpretive semiotics and mass media

Toni Marino, Inference in Media Space

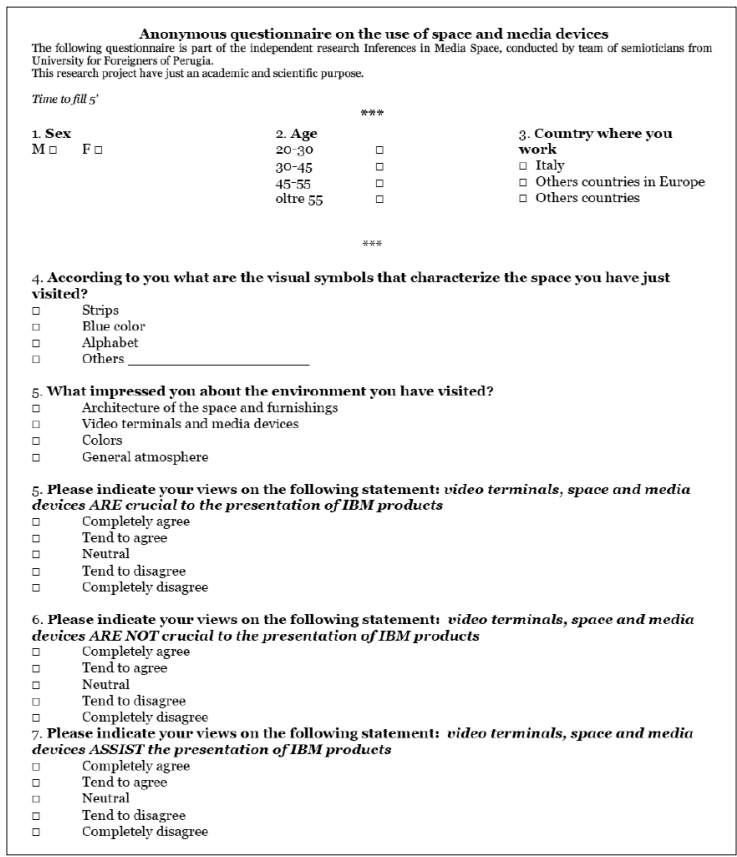

Exhibit 1. Questionnaire to IBM customers.

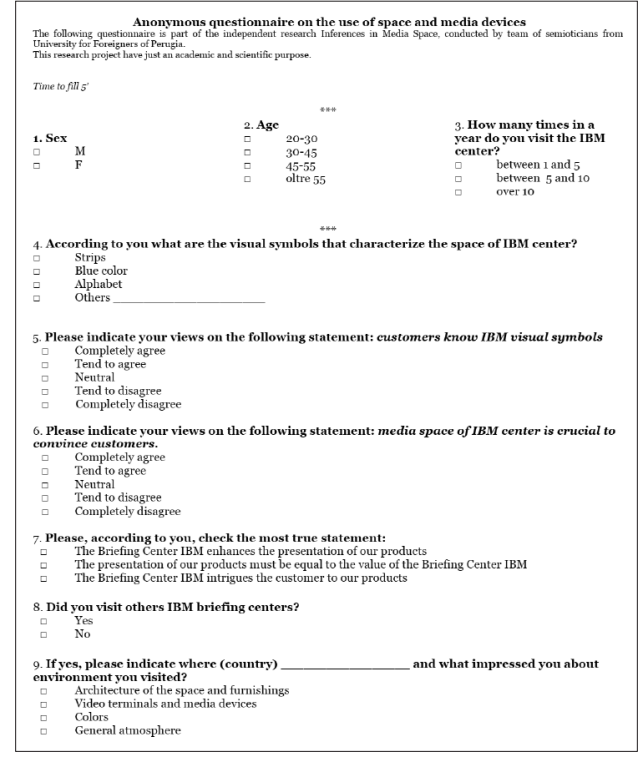

Exhibit 2. Questionnaire to IBM members. 
Which of the following statements do you consider to be most real?

$\square \quad$ The IBM Briefing Center enhances the presentation of our products

$\square \quad$ The presentation of our products must measure up to the aesthetic standard of the IBM Briefing Center

$\square \quad$ The IBM Briefing Center entices the customer to buy our products.

The three answers, in the order in which they are presented, translate three hypotheses on the customer's inference:

1. Deduction - customer evaluates the product as a specific case of the know-how of the IBM brand;

2. Induction - customer evaluates first the product and consequently assigns a value to the IBM brand;

3. Abduction - customer evaluates the product on the basis of an emotional manipulation that causes him/her to give a high evaluation of the IBM brand.

In the questionnaire aimed at clients, we asked two questions about the elements that characterize the Center, and three questions to be answered by assigning a value to three statements by means of a 5-point Likert scale. These statements translate respectively the three types of inferences: deduction, induction and abduction. The three statements are:

QUESTION N. 5 Please, indicate your views on the following statement: video terminals, space and media devices ARE crucial to the presentation of the product

$\square$ Completely agree

$\square$ Tend to agree

$\square \quad$ Neutral

$\square \quad$ Tend to disagree

$\square$ Completely disagree

QUESTION N. 6 Please, indicate your views on the following statement: video terminals, space and media devices ARE NOT crucial to the presentation of the product

$\square \quad$ Completely agree

$\square$ Tend to agree

$\square$ Neutral

$\square \quad$ Tend to disagree

$\square$ Completely disagree

QUESTION N. 7 Please, indicate your views on the following statement: video terminals, space and media devices ASSIST the presentation of the product

$\square$ Completely agree

$\square$ Tend to agree

$\square$ Neutral

$\square \quad$ Tend to disagree

$\square$ Completely disagree 


\section{Ocula $a^{15}$}

Commemorating Charles S. Peirce (1839-1914): interpretive semiotics and mass media

Toni Marino, Inference in Media Space

In the first case, the claim attaches greater importance to the media space and thus predetermines its value. A high index of agreement on this statement may indicate a deductive approach to the media space. Moreover, the questionnaires were submitted after the presentation of the product, so the agreement on this statement confirms that the logical reasoning proceeds from a major premise which assigns a high value to the space of the IBM brand. The value of the product is deduced from the value of the setting.

In the second case, the statement indicates a logical process that starts from the top value of the product and moves to the general value of the environment.

In the third, the claim links media space and the presentation of the product, and indicates a process of input processing that associates IBM media space with IBM products.

In the first draft of the questionnaire, the three questions evaluating the inferential process put in place by customers were structured as a feedback about the brand (Please, indicate your views on the following statement: IBM is a brand with high quality know-how in Information Technology [deduction]; IBM is a brand with high quality products and services [induction]; $I B M$ is a company with high quality employees [abduction]). In this way it was possible to evaluate the argument made by the customers starting from the judgment that it produced in the mind of the customer, without direct reference to the media space. However, this type of processing was rejected by the IBM Marketing Department that deemed it inappropriate during the negotiation of products.

\section{The case study: IBM Briefing Center - Rome}

As previously mentioned, the concept of the IBM center is to develop architectural cues based on the stripes that form the IBM logo. The use of lines as an extension of this concept is found in the various elements, from the veining of the woodwork to the design of the glass partitions of the rooms and the white finish masking the columns. The whole space has a very distinctive layout conceived to stimulate an intuitive flow in the visitors as they move through the interiors (Dardarananda 2012).

The IBM Center is an immersive and semantically controlled environment. Visitors are guided along paths marked by the architecture of the space. The windows, for example, are screened to ensure a constant flow of light and give a controlled perimeter to the visitor's vision. Peirce's so-called "collateral observation" for interpreting new media messages seems impossible (Ipsen 2003) in the Center. The entire project starts with the goal of having briefing rooms that are welcoming and provide unobstructed views of the presentation screens, eliminating the typical office layout of modular rectangular spaces, and offering a clearer perception of the spatial volume compared to the rest of the building (Dardarananda 2012). 


\section{Ocula $a^{15}$}

Commemorating Charles S. Peirce (1839-1914): interpretive semiotics and mass media

Toni Marino, Inference in Media Space

\subsection{Media space in the IBM Briefing Center}

The IBM Center is a complex media device, whose main feature is the search for homogeneity in the structure. It extends over two bodies of the building starting from the entrance hall, where the IBM logo is exhibited. Here visitors find themselves standing in front of a glass-walled room containing large machines for processing calculations, the historical symbol of IBM know-how (IBM is a leader in the design of server machines). From the entrance hall visitors are welcomed into one of the four discussion rooms, which differ in size, space, design and use of media devices including video. Moreover, in the Center there is a briefing room intended for the socializing that follows the presentation of products.

The environmental organization has two important elements: (i) "transparency", guaranteed by the use of glass, which if necessary can be screened with curtains, and the use of gloss white surfaces, where the light slips and guarantees the original idea of the flow; (ii) "symbology of media", designed as a journey through video devices. Once inside, the visitor encounters a considerable number of screens entirely managed by the staff of the Center who can plan their content, the information they contain and background themes. Some of these devices are intended for the entertainment of the visitor having a value that is purely symbolic and conveying general information about the group and IBM solutions. Other devices provide the visitor with information about the activities that are taking place in the Center (where, when, who). The video devices in discussion rooms are utilized for the presentation of the products.

Transparency stimulates a passional process in the visitor which is accompanied by the design of the colors and background music. It should be pointed out that the colors in the Center can be programmed according to different themes. The value of transparency is crucial in the use of space. In fact, it is an element that unlike any other - including video devices - cannot be replaced without totally redesigning the Center. The interpretation of transparency mechanisms are governed by universal rules and are less subject to cultural trends.

The symbolism of the media is a feature of the environment and part of the design and furnishings of the Center. It was planned with the possibility of being renewed. Right from the entrance of the IBM building, visitors encounter many screens. One in the reception area of the building displays the founder's statement, "This is a company of human beings not machines, personalities not products". Then there is another screen as soon as visitors reach the elevator to go to the Briefing Center. This second screen transmits information about the presentations on programming. So once inside the Center, visitors literally take a trip measured by small screens, which broadcast content in line with the thematic areas of the client, or alternatively show IBM high social impact solutions such as medical research and man-machine interaction. In the rooms, however, visitors are involved in an immersive presentation guaranteed by backlit screens, high-resolution video and large dimension screens. 


\section{Ocula $\mathbf{a}^{15}$}

Commemorating Charles S. Peirce (1839-1914): interpretive semiotics and mass media

Toni Marino, Inference in Media Space

In the case of the screen, transparency has the technical meaning suggested by Bolter's use of the term (Bolter, Grusin 1999) where it stands for the absence of frames that mark the boundaries between media spaces. Media transparency and symbolism are melded to achieve just one effect, namely to provide the visitor with a homogeneous, smooth and obstacle-free path.

\subsection{Point of view of IBM}

The design of the Center was overseen by IBM managers and the architects Iosa Ghini Associati of Bologna. The basic features of the Center reflect the threefold intentions of IBM: resistance to the obsolescence typical of symbolic environments; the high value to be given to video devices without creating divisions between technology and the environment; the Italian character of the Center.

With regard to cultural obsolescence, the Center has been designed so that it can be renewed over time. The media wall in the Fermi Briefing Room (see Exhibit 3), made in starglass by Stewart Filmscreen, for example, is mobile and can be replaced. The colors and materials give a sense of abstraction which can be seen in the glacier white corian for the tables, walls or columns while a feeling of naturalness is created by the use of wood and glass. The video terminals which operate the symbolic information permit a continuous renewal and are less static than posters.

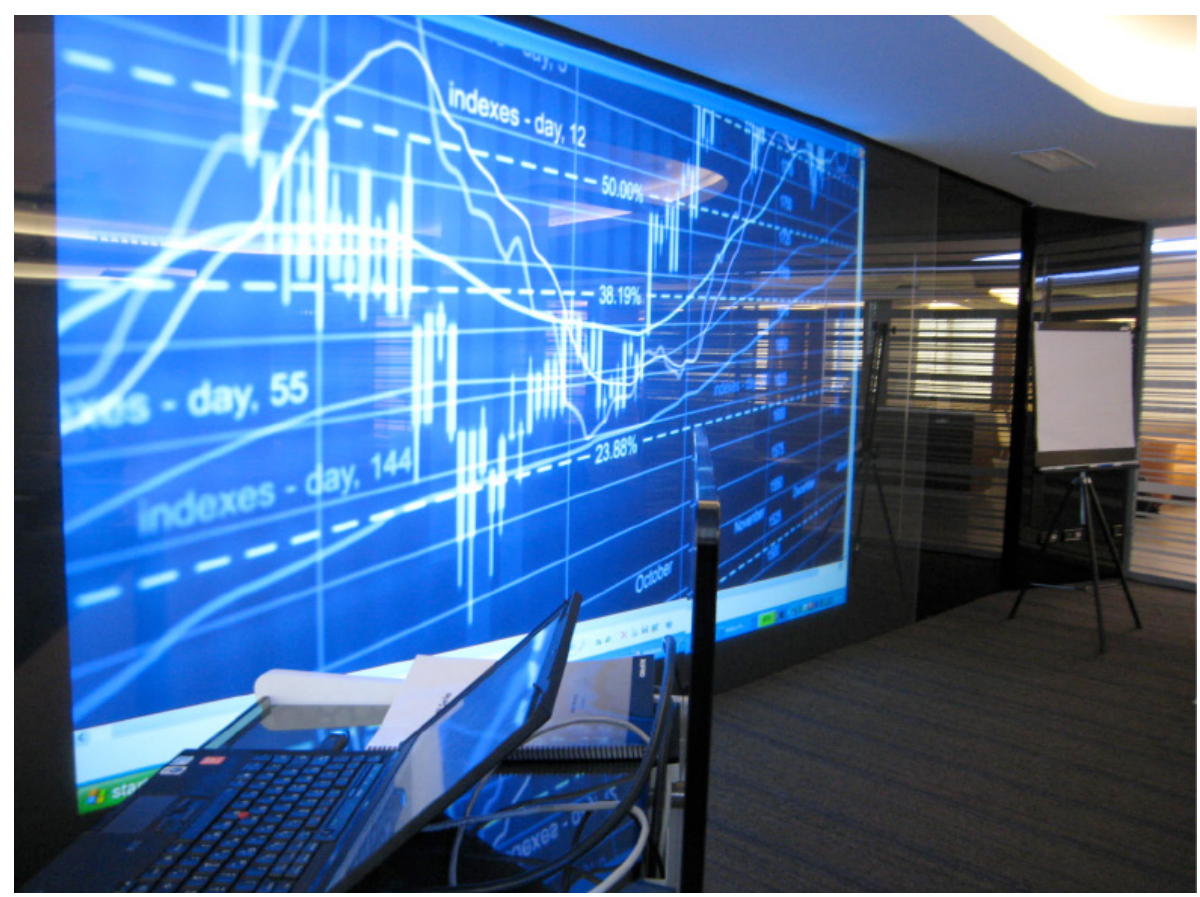

Exhibit 3. Media Wall in one the Fermi Briefing Room.

The video terminals are divided into two main groups: solutions for audiovisual functionality in the briefing rooms and solutions that implement the architect's concept of the visual impact throughout areas in the 


\section{Ocula $a^{15}$}

Commemorating Charles S. Peirce (1839-1914): interpretive semiotics and mass media

Toni Marino, Inference in Media Space

Center (Dardarananda 2012). To achieve both aims, the video devices use a seamless projection effect. The key requirements are that the video has to be as large as possible; it has to have resolution and color fidelity so that the material, which is color-coded, remains intelligible; it is important for the light of the projection not to strike the presenter and cast a shadow (every video has a rear projection); they must be fully integrated with the architecture.

The Italian character of the Center has been created using two particular features: firstly, the naming of places, for example the rooms have the names of "The Kids of Via Panisperna", symbol of Italian excellence in science and secondly, the concept of authorship. Every single thing in the Center is designed to be understood as part of a whole, as the work of a single author which can be seen even in the chairs, columns, lamps and tables. By choosing an interior designer like Iosa Ghini who is also a designer, has guaranteed that assemblages between objects and space are not forced.

\section{Semiotic processes in media space of IBM Briefing Center}

We belive that the organization of space in the Center promotes processes of interpretation that play on three hypothetical interpretive reasonings, each related to one of the three types of inference.

The first is deduction, in which the major premise is the corporate image of IBM (the visitor-client thinks IBM is the leader in IT solutions and has high quality know-how), the minor premise is the individual presentation (the visitor-client notes: this is an IBM product), and the result is the value of the product (the visitor-client deduces: the product is of high value). The second is induction, in which the value of the product (the visitor-customer notes: the product is of high quality)is considered as a fact of experience, the premise is its belonging to the IBM group (visitor-client thinks: this is an IBM product) and the result is a general rule about the corporate image of the company (the visitor-client induces: IBM solutions are of high value). The last is abduction, where the visitor-client knows the corporate image of the company and the relationship between the company and solutions, but he wants to treat the relationship between company and product as a hypothesis. It is a kind of reasoning derived from skepticism (the visitor-client assumes: I do not know if this is an IBM product).

These processes are not purely logical, but they are rhetorical arguments which are based on the company's ability to convince the customer of its quality and solutions (product value, the value of IBM, connection between IBM and the value of IBM products). We can understand the media space of the Center as a rhetorical argument that demonstrates the value of the brand and its products, and that favors some interpretive processes made by the customer, or tries to find answers to the interpretive doubts. For each of the three inferences put in place by the visitor-client, the Center responds with as many paths and arguments based on the symbolism of the media. 


\section{Ocula $a^{15}$}

Commemorating Charles S. Peirce (1839-1914): interpretive semiotics and mass media

Toni Marino, Inference in Media Space

\subsection{The path of deduction}

Deductive reasoning is the inference that is implemented by the "loyal visitor", that is the majority of visitors to the Center. These are visitors who come to IBM because of the reputation of its trade mark or as it is a leader in certain IT sectors. In this case, as already mentioned, starting from the major premise contingent on the value of the brand, each visitor deducts the value of the product on a statistical probability based on past experience, market data and so on.

Many signs in the Briefing Center support inferences of this type. Not surprisingly, there are also marketing protocols which are useful for ensuring a fair representation of the corporate image; for example, the position of the logo inside and outside the Center or the cadence with which the video terminals alternate references to the IBM brand. These are procedures that refer primarily to market data (perception of the brand, target, etc.) and to information that has statistical validity. In the Rome Briefing Center, the detail that arouses the greatest interest is its Italian character; to achieve this aim each element in the Center, instead of being mass-produced, was designed as a single piece. The Center itself is signed. In the hall next to the logo of the brand appears the signature of Massimo Iosa Ghini (see Exhibit 4). It is a detail that breaks with the design space typical of other Briefing Centers of the same brand.

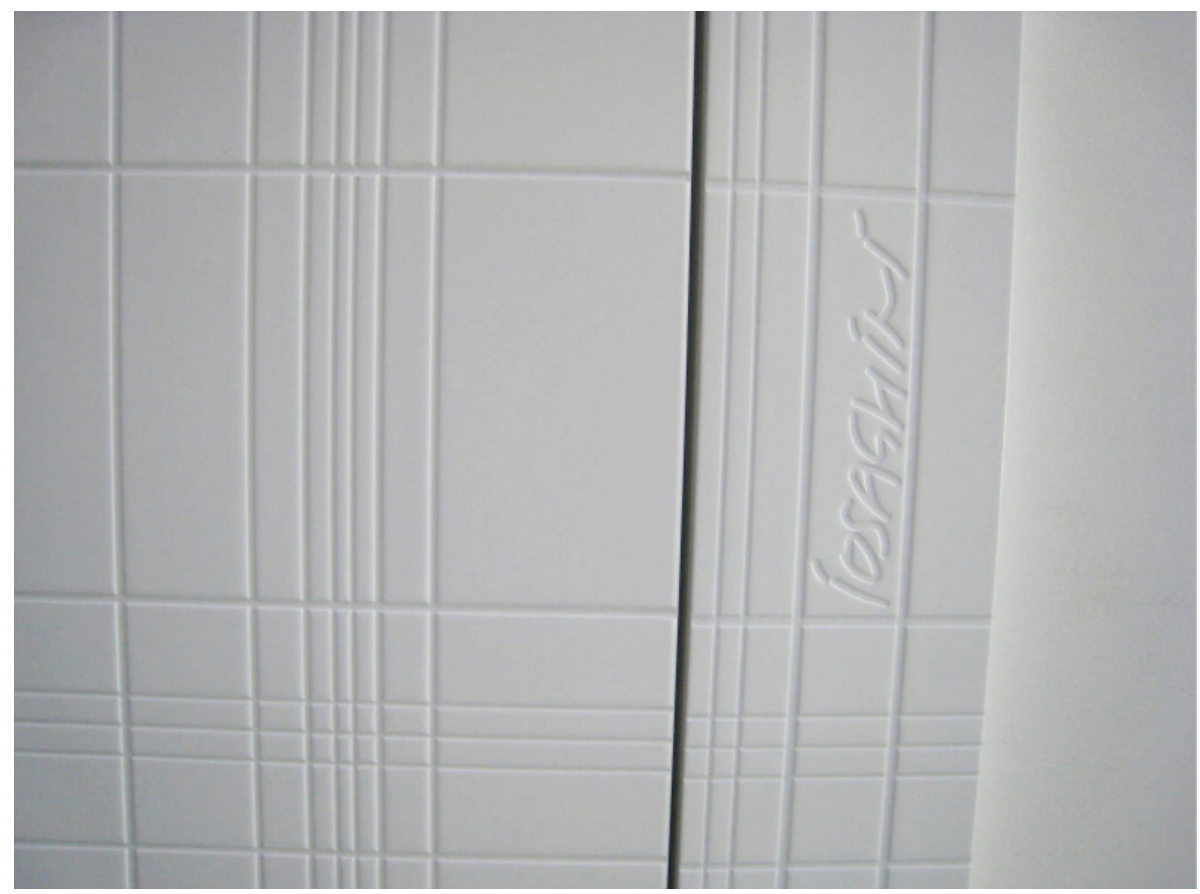

Exhibit 4. Author's signature on the wall of the center.

In this case, however, the brand stands both as inspiration for a creative process (the curved lines inspired by the orthogonal lines of the IBM logo), and as commissioner of works of art, and so the visitor performs a sort of 


\section{Ocula $a^{15}$}

Commemorating Charles S. Peirce (1839-1914): interpretive semiotics and mass media

Toni Marino, Inference in Media Space

parallel inference that combines the high value of IBM as commissioner of product design with the premise of the high value of IBM in IT.

\subsection{The path of induction}

Inductive reasoning is implemented by the "curious visitor", a type of visitor for whom the brand is not synonymous with high value in IT. There may be companies that have turned to IBM for solutions that address very innovative sectors, where the IBM experience is less relevant, or where there are many competitors. In these cases, the visitor will adopt inductive reasoning. This reasoning can lead both to the rule that assigns a higher value to the brand and to the rule that assigns an opposite value. It is a very common process of evaluation where, according to the assessment of individual products, the value of the corporate image is confirmed, increases or decreases. In response to inductive reasoning, media space is designed to communicate an idea of system: not the corporate image of IBM but an abstract idea of corporate image. The design communicates an idea of system not immediately linked to the IBM brand. Many signs in the Briefing Center are not designed to give an invasive idea of the IBM brand but to let the brand establish itself in the mind of the visitor in a natural way. The most important of these signs is the use of the brand lines as guidelines in the space of the Center. In addition to this, there is the use of video devices that offer information - mostly visual - about new brand projects, calculating how often these references to the brand are shown. In this way, the visitor will make the following reasoning: the product that was introduced to me is of high quality - the product that was introduced to me was constructed by a company - this company is IBM - IBM is a high quality company. The space of the Briefing Center allows the addition of a further logical step in the induction. In this way, the general rule (the high quality of IBM), will be less linked to the individual products and more to an idea of the production system, or capacity of that brand to be configured as a system.

\subsection{The path of abduction}

The reasoning that shows the rhetorical value of the argument most clearly is the abduction of the "skeptical visitor". In this case, the visitor submits the deductive syllogism to logical criticism and unmasks its rhetorical value. The visitor assumes that the high value of the company is not binding in the purchase of a single product. So the fact that the product is an IBM product is not binding when making a choice. The skeptical visitor is aware that there is not a logical relationship between the high brand value and a single product. $\mathrm{He}$ will evaluate the product without correlating it with the brand.

In response to the skeptical visitor, IBM media space adopts the rhetorical argument of "intuitive flow". The visitor is subjected to an immersive experience that produces a strong emotional impact, what Dardarananda (2012) called the 'wow' experience. The signs of technology, the seamless effect, transparency and slippage of light, are the elements of a fictional experience, in which the visitor produces the process of the suspension of dis- 


\section{Ocula $a^{15}$}

Commemorating Charles S. Peirce (1839-1914): interpretive semiotics and mass media

Toni Marino, Inference in Media Space

belief (Brand 2008). The intuitive flow provides an answer to cases where what might be seen as a probable conjecture (IBM high value $=$ high value of its products), is instead treated as an abduction by the visitor (Is there a relationship between this product and the value of IBM?). The intuitive flow causes the general rule that IBM "always" produces high-quality solutions to be replaced by a rule governed by the emotions but the logical information which results remains the same: IBM IT products are of high value. The visitor, therefore, will link the product to a general rule that suggests the emotional high technological value of that space, and he/she will make a positive evaluation (see Exhibit 5).

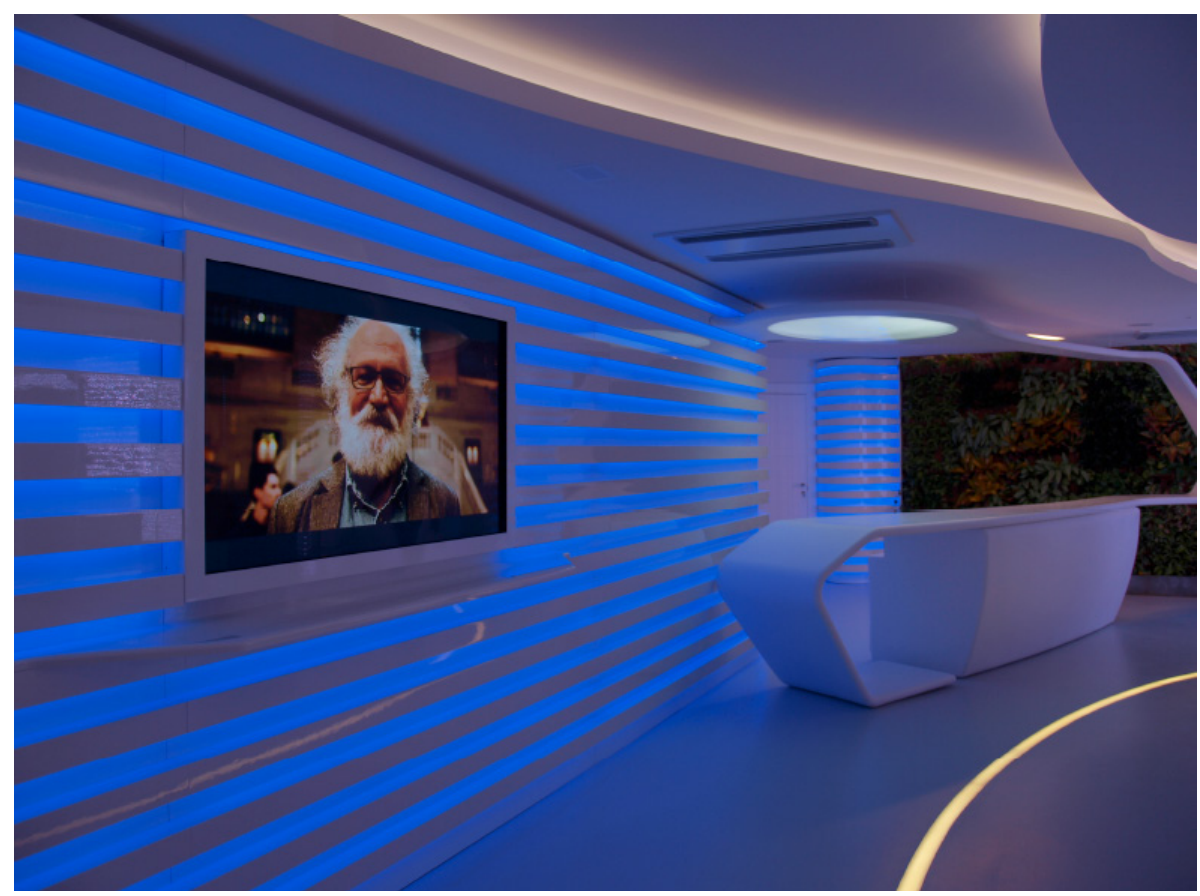

Exhibit 5. Example of Intuitive flow.

In this case, the space favors the loss of statistical logic as a guide in the search for truth. The doubt harboured by the skeptical visitor is the low value of the statistic for single occurrences. Skeptical visitors are small companies that make investments in individual products, and consider their case unique with respect to general cases. The intuitive flow favors non-statistical reasoning (IBM high-value, high probable value of all its products) responding to it with an emotional experience, in which the signs of the technology become playful elements for visitors as they pass through the Center. It is a process similar to what Magnani (2011, p. 220) refrs to as manipulative abduction based on reasoning by doing or externalization of reasoning. In this case, the outsourcing of reasoning occurs within a controlled space, which provides the visitor with objects on which to base his/her judgment.

The stronger the suspension of belief in the outsourcing process, the stronger the strengthening of the beliefs will be during the return to pure logical reasoning. The more radical the suspension of the statistical rule, the more 


\section{Ocula $a^{15}$}

Commemorating Charles S. Peirce (1839-1914): interpretive semiotics and mass media

Toni Marino, Inference in Media Space

radical this belief will be at the end of the fictional experience when the visitor will confront rules of fiction and rules of reality.

\section{Results of questionnaire}

In the IBM employees' responses, the most important topic is the absence of a relationship between the media space and the inductive process. IBM employees are convinced that visitors-customers can implement only two inferences: deduction (The IBM Briefing Center enhances the presentation of our products) and abduction (The IBM Briefing Center entices the customer to buy our products). Moreover, deduction appears to be the most likely hypothesis (over 75\%).

The responses regarding the function of the Center and the visual characteristics of the brand are the same: IBM employees believe the customer is already aware of the brand and considers the IBM Briefing Center a useful tool for convincing the client. They also believe that the color blue and the lines are important elements of the Center.

The majority of IBM employees consider the lines and the color blue to be directly attributable to the IBM brand and not seen as a nuance. They also assume that the visitor-client associates these elements with the IBM brand in a direct way. In our analysis, however, they represent the elements that mainly favor abduction (intuitive flow). This partial difference could be explained by the strong identification between IBM employees and the company.

The answers given by the customers differ from those of the IBM employees. They consider the stripes and the color blue as elements of the media space of the Briefing Center that can stimulate either a deductive or an abductive process. In fact, visitors-clients totally agree with the statements 5 and 7 of the questionnaire whereas they do not agree (unlike IBM employees) with the statement that describes an inductive process. The views expressed in statement 6 of the questionnaire show a negative or neutral rating. Visitors do not consider the time of the visit to the Briefing Center as an opportunity to express an opinion on the IBM brand. The visit to the Center is seen as a concrete opportunity for product evaluation. In fact, they noted that the elements of the Center confirm the visual expectation towards the brand (blue lines and the color of the logo). Furthermore, in our analysis we considered the deductive and the abductive processes as being partially overlapping. In the first case the "convinced visitor" makes a linear evaluation; in the second case, the evaluation is also linear but the visitor avoids applying the rules of deduction to a single occurrence thus showing a skeptical attitude. The inductive process is unlikely and almost never occurs because the corporate communication of the IBM brand is very successful. One possible reading of the association between the lines and colors of the Briefing Center and the high value of the brand is the great success of the architectural design of these elements. They act, evidently, at a more emotional and passional level than a purely logical one. Most of the visitors, therefore, perform an emotional inference - emotional abduction - that associates the media space with the high value of the IBM brand. 


\section{Ocula $a^{15}$}

Commemorating Charles S. Peirce (1839-1914): interpretive semiotics and mass media

Toni Marino, Inference in Media Space

\section{Conclusions}

The study of the inferences of visitors in the space of the IBM Media Briefing Center has made two considerations possible: one regarding the methodology of analysis, and another on abduction.

Regarding the methodology, the study shows that the analysis of communication texts produces inaccurate results. In the case described in this paper, a simple question put to people involved in empirical communication allows us to recreate correctly the context of communication. This context excludes the possibility of "curious visitors" assumed in the analysis of the space. This observation is of great value because it refutes a hypothesis of textual interpretation in that in the analysis of space we have hypothesized the existence of a curious visitor who in reality does not exist. The textual analysis confirms its validity for the study of very well-known empirical contexts of communication. In other cases it is preferable to link the interpretive analysis of texts with a study on the people involved in the communication.

This conclusion is actually already contained in Peirce's theory. The philosopher describes the framework of a propositional semiosis where there are qualitative relations between signs and possible interpretations. These relations are computable on the basis of statistical occurrences compared to a more general class. The rate of truth of inferences decreases by moving from Statistical Deductions to Probabilistic Deductions, and then to Inductions up to Abduction.

As for abduction, it is relevant to the study of inferential processes guided by the passions or sensory stimuli, not so much for what they can gain in terms of theories of communication and new media (already studied in marketing, theories of perception or from studies on cognitive memory), but in relation to the study of media as stimulators of fictional paths. In particular, it seems interesting to investigate the re-entry from the fictional world to the world of reality, and the relationships that are established between the inferential processes in both spaces. If, like Peirce, we consider abduction as 'the only possible hope of regulating our future conduct rationally', we can investigate the fictional worlds and products of creativity such as art, film, literature and architecture as models of abduction and use them, as suggested by the Behavioural Sciences, as stimulators of new points of view on reality.

\section{References}

Anderson, Douglas R.

1987 Creativity and the Philosophy of C. S. Peirce, Dordrecht, Netherlands, Martinus Nijhoff Publishers.

Bolter, Jay David; Grusin, Richard

1999 Remediation. Understanding New Media, Cambridge (Massachusetts), MIT Press.

Brandt, Line

17 | Novembre 2014 | www.ocula.it 


\section{Ocula ${ }^{15}$}

Commemorating Charles S. Peirce (1839-1914): interpretive semiotics and mass media

Toni Marino, Inference in Media Space

2008 Literary Studies in the Age of Cognitive Science, "Cognitive Semiotics", 2, Spring, pp. 6-40.

Dardarananda, Peter

2012 Agora. Form and Technology - IBM Software Executive Briefing Center, Roma, Electa.

Davies, Sarah R.

2008 Constructing Communication: Talking to Scientists about Talking to the Public, "Science Communication", 29, pp. 413-434.

Eco, Umberto

1976 A theory of Semiotics, Bloomington, Indiana University Press.

Gilles, Fauconnier - Mark, Turner

2003 The Way We Think. Conceptual Blending and the Mind's Hidden Complexities, New York, Basic Book.

Gaines, Elliot

2014 Media Representations of Science, and Implications for Neuroscience and Semiotics, "Semiotica", 200, pp. 103-117.

Gaines, Elliot

2008 Media Literacy and Semiotics: Toward a Future Taxonomy of Meaning, "Semiotica”, 171, Pp. 239-249.

Kruijff, Geert-Jan M.

2005 Peirce's Late Theory of Abduction: A Comprehensive Account, "Semiotica", 153, pp. 431-454.

Hanson, Norwood R.

1958 Patterns of Discovery, An Inquiry into the Conceptual Foundations of Science, London, Cambridge University Press.

Ipsen, Guido

2003 The Crisis of Cognition in Hypermedia, "Semiotica", 143, pp. 185-197.

Lee, Yunhee

2012 Narrative Cognition and Modeling in New Media Communication from Peirce's Semiotic Perspective, "Semiotica”, 189, pp. 181-195.

Magnani, Lorenzo

2011 External Diagrammatization and Iconic Brain Co-Evolution, "Semiotica", 186, pp. 213-238.

Marusek, Sarah (ed)

2012 Visual Semiotics of the Spaces We Inhabit, Special Issue of "International Journal for the Semiotics of Law", Springer, 27. 


\section{Ocula ${ }^{15}$}

Commemorating Charles S. Peirce (1839-1914): interpretive semiotics and mass media

Toni Marino, Inference in Media Space

Paavola, Sami

2005 Peircean Abduction: Instinct or Inference?, "Semiotica”, 153 , pp. 131-154.

Peirce, Charles S.

1960 The Collected Papers of Charles Sanders Peirce, vol. II, Element of Logic, Charles Hartshorne, Paul Weiss, and A. W. Burks (eds.), Cambridge (Massachusetts), Harvard University Press.

Petrilli, Susan; Ponzio, Augusto

2005 Semiotics Unbounded. Interpretive Routes Through the Open Network of Signs, Toronto, University of Toronto Press.

Simone, Raffaele

2012 Presi nella rete. La mente ai tempi del web, Milano, Garzanti.

Thom, René

1975 Structural Stability and Morphogenesis. An Outline of a General Theory of Models, London, The Benjamin-Cummings Publishing Company.

Toni Marino, MA in Literature, MA in Publishing, Phd in Science of Book and Writing. Currently he is Research Fellow at The University for Foreigners of Perugia, where he participates in research projects on Women's Fiction, Advertising, and Journalistic texts, and visiting lecturer in Semiotics at the University Roma Tre His research interests are mainly oriented to Visual Semiotics, Narratology, and Theory of Litearture. His practice focuses is the relationships between the visual and verbal codes.

He is co-author of Scrittori e pubblicità (2011) and author of Gender in Italy. Processi di canonizzazione della letteratura femminile (2014). Among his publications La lettura dell'immagine in testi sincretici; Grandi scrittori e made in Italy; Women's writing women's reading; Plot Placement and Literary Plot: How Economic Context Becomes Part of Literature. 